\title{
A CALL TO DENTAL NURSE EMPLOYERS TO INCREASE SALARIES AND PROVIDE EDUCATIONAL SUPPORT
}

\section{BADN Presidential column by Jacqui Elsden}

B ADN's campaign, launched in August 2020, called to the profession for the recognition of dental nurses in acknowledging the valuable work that you do, not only during the global pandemic but every day you are at work.

This call to action was multi stranded.

We said: 'Dental nurses are registered dental care professionals and must be recognised as such - by employers, by colleagues and by the NHS. BADN are calling for all dental nurses in practice to be paid a salary which recognises not only their invaluable contribution to the dental team but also their training, knowledge and professionalism, as well as the financial outgoings required just to be allowed to work as a dental nurse - training costs, registration fees, indemnity cover and CPD costs - not just minimum wage...

'In addition, dental nurses employed in NHS practices are not considered to be NHS employees and consequently are not afforded the same conditions and benefits as NHS employees. They are denied access to the NHS pension scheme, are not paid according to NHS salary scales but instead are often paid just minimum wage. Nor are they issued with NHS ID - and consequently were not recognised as key workers during the lockdown period...

'BADN are also calling upon the GDC to lower the ARF for dental nurses - or, at the very least, allow monthly payments in order to ease the financial burden...'

We were disappointed that despite many requests from us to waive the $\mathrm{ARF}$ or at the very least allow monthly payments, the GDC still went ahead and requested the ARF in full by 31 July 2021.

In March 2021 we welcomed the news that the GDC had decided to allow quarterly ARF payments.

We said '...£114 per year is still too high a fee for dental nurses, particularly given the circumstances of the last year when many dental nurses were not paid their full salaries (or even, in some cases, paid at all), but the GDC refused a request by BADN in 2020 to lower the ARF, even temporarily.
We are however pleased that they have at least finally acknowledged one of our proposals by allowing dental nurses to pay the ARF in instalments...

'Whilst this is a good start, I would like the GDC to give further consideration to our two other proposals: that the ARF be lowered to a more realistic figure for dental nurses, and that a lower ARF be implemented for all dental professionals, not just dental nurses, who work part time.'

In January 2021, we welcomed the news regarding Key Worker status for dental nurses.

\section{'In January 2021, we welcomed the}

\section{news regarding}

Key Worker status

\section{for dental nurses'}

We said: 'Because government statements did not specifically include dental professionals in their list of key workers, many dental nurses have experienced problems in accessing childcare, leaving them unable to go to work - and many dental employers have been unsympathetic to their situation. Clarification on the key worker status of dental professionals in the latest update from Sara Hurley:

"dental professionals are defined by the Government as critical workers. The Government website says 'This includes, but is not limited to, doctors, nurses, midwives, paramedics, social workers, care workers, and other frontline health and social care staff including volunteers'. Front line health staff includes dental professionals and their teams..."

More recently we welcomed further good news for dental nurses related to our campaign where $\{$ my $\}$ dentist stated: '...As of 1 August 2021, \{my\}dentist dental nurses will receive an average pay increase of 5.5\%, increased annual leave entitlement, payment of the GDC ARF and medical indemnity insurance. Educational support includes an NEBDN-accredited student dental nurse training programme together with "Flourish" - a development programme for qualified dental nurses in collaboration with BADN...'

Tom Riall, chief executive of $\{\mathrm{my}\}$ dentist, said: 'Our dental nurses have given extraordinary support during the pandemic, making a huge difference to our patients across the UK, and supporting our clinicians to grow their private revenues at the fastest rate on record. I'm really pleased that we've been able to make this investment which has been designed to recognise the crucial role of our dental nurses and to reward their long service and outstanding experience'.

I am delighted that $\{$ my $\}$ dentist have recognised the important role of dental nurses within the dental team and are providing both financial and educational support to their dental nurses, leading to a transparent structure and a clear career pathway.

I would now call upon other employers, particularly corporates, to follow $\{$ my dentist's example in recognising dental nurses as valued members of the dental team, increasing dental nurse salaries, and providing educational support.

We are happy to work with any employers wishing to support their dental nurses and I invite you to contact BADN's Chief executive in the first instance, pam@ badn.org.uk.

I am continuing to push forward our campaign at every opportunity, along with my BADN Executive Committee colleagues, in order to achieve success in the remaining areas of our national campaign.

For more information about how to join BADN, go to www.badn.org.uk; all other enquires please email enquiries@badn.org. uk. 